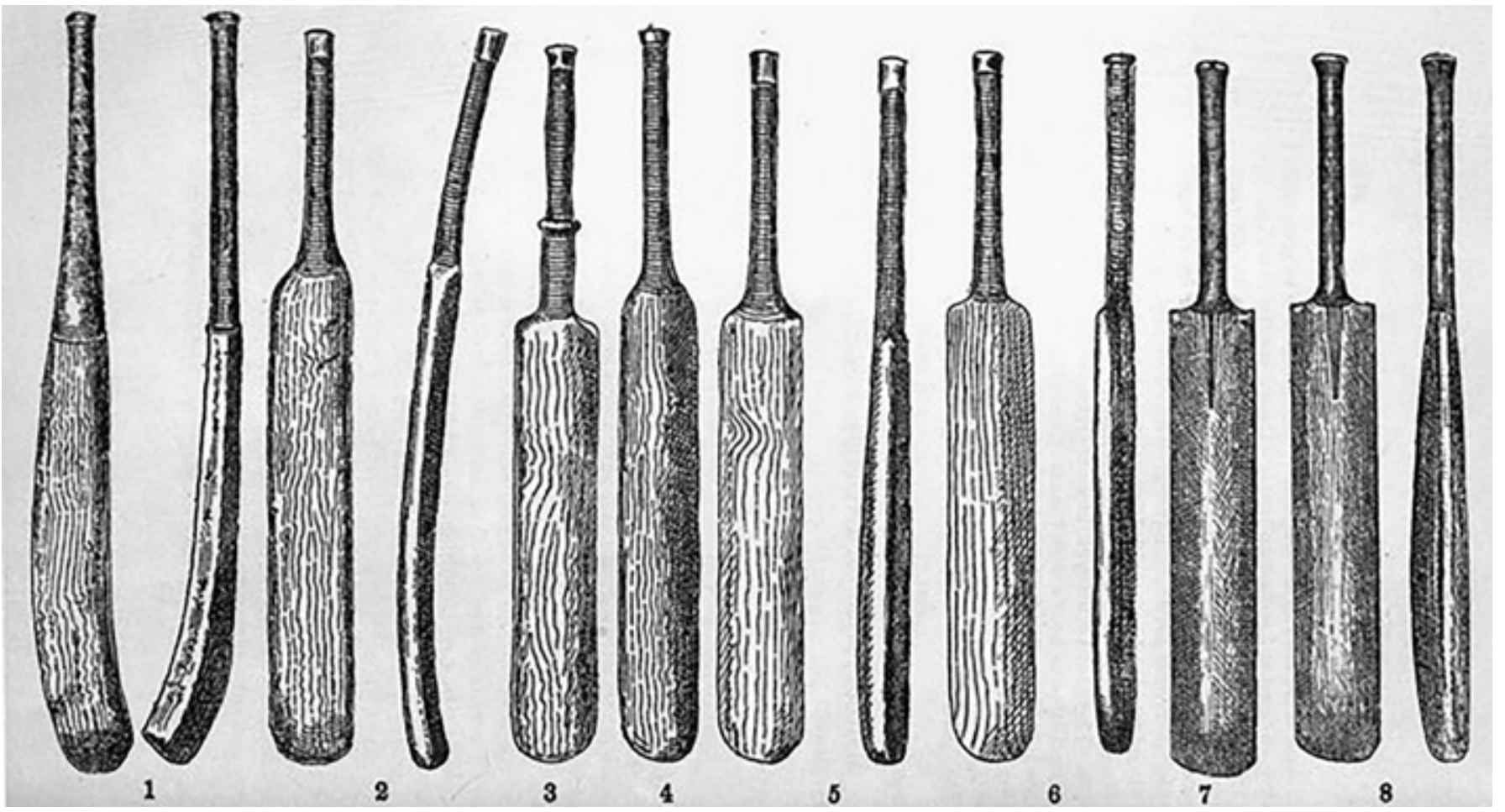

Figure 1: Bats. (Grace, 1891)

\title{
What is it like to see a bat?
}

Richard Herriott,

Design School Kolding, Kolding, Denmark

\section{ABSTRACT:}

The article examines inadequacies of design research regarding the treatment of appearances of objects or, in other words, those aspects which are qualitative and psychological. It presents a division of design research into meansbased and ends-based inquiry. Design's relation to art, planning, engineering and social science is presented to make clear how design research may overlook the intuitive in pursuit of objectively legitimate explanations. A tentative description of the core of design is offered followed by an analysis of how designers approach aesthetic judgements. The distinction between intuitive design and process-based design is explained. This relates to a question posed by Hillier (I998) concerning design's relation to processes and form. Finally, a case is made for an art-criticism approach to design research, one which addresses the meaning of form.

Keywords: design process, design research, design methods, aesthetics.

\section{INTRODUCTION}

Without wishing to reduce the value of existing branches of design research, a case can be made that this research is inadequate. Much design research does not address the qualitative in design, that part of design which exists in drawings, in the physicality of products and "what it is like to perceive a designed thing". Design research is neglecting the intuitive, non-verbal aspects of design and the meaning of the object or its parts.

The article is structured as follows. Firstly, it explains how the development of design research has downplayed the aesthetic aspects of design. Design research has been interested primarily in methods and objectives: respectively how to plan a design process and how to achieve defined objectives such as accessibility, acceptability or usability. Design research on aesthetics has inquired into visual cognitive process or dealt with 


\section{5) As in the philosophy of consciousness where there is a divide between dualist and materialist approaches, there is also a parallel division in design research. "}

consumer attitudes. Secondly, in order to make clear the aesthetic core of design, the paper shows design's relation to art, planning, engineering and social science. It is argued that the wish to pursue "legitimate" design outcomes has put a strong, materialist emphasis on process. However, the core of design is an intuitive activity that occurs in the relation of the designer to the idea of the object, its visual representation and instances of the idea. Thirdly, the paper then proposes that the meaning of form be addressed so as to acknowledge the subjective quality of designed objects in contrast to engineered objects. This is on the basis of the idea that art methods introduce the issue of meaning and the subjective that is absent from both design as planning and the design of engineering solutions that satisfy objective needs.

In terms of delimitation, this paper does not address artistic design research. In Frayling's terms (I993) this is research through design. This paper discusses research into design, the output of which is written documentation. Research through design's output is the object itself and documentation about the process and/or the final objects. A considerable body of work exists regarding the discourses of design research and design practice and industrial design versus technical design. A satisfactory treatment of these discourses would require more space than is available so in this paper the focus is on modern design research, starting with the Design Methods movement of the I96os.

Design can be analysed at the levels of practice, tools and theory. Using Love's (2000) meta-theoretical structure for design theory this article deals with design methods, design process, theories of internal processes, and ontology of design.
In his paper "What is it like to be a bat?" Nagel (I974) addressed the nature of consciousness by inquiring into the subjective experience of a creature very different from humans. Particularly, he was drawing attention to the way the bat perceived its surroundings. Nagel argued that materialist accounts of the mind did not deal adequately with the essential, subjective component of consciousness, which is that there is something that it feels like to be a conscious being, for example, a bat. A conscious being could be said to be conscious if it could experience or sense that state. The longer argument as to whether consciousness can or can't be explained by reductionist theories has not being resolved although authors such as Chalmers (I996) have attempted to propose a dualistic explanation of the mind phenomenon. At one level, this article draws upon Nagel by asking about how designers see and how design is perceived; it also asks if design research can account for how one sees as a designer.

As in the philosophy of consciousness where there is a divide between dualist and materialist approaches, there is also a parallel division in design research. This division in design research is possibly tacit: the objective character of design is well-covered. The subjective character, what it is like to see a designed object, its impressions and meanings are not so well handled. We might be able to define the geometry of the bat (see Figure I), we can discuss the design process of the bat's creation and can determine what percentage of users are satisfied with its appearance and functionality. But that is not the totality of what it is like so see the designed object. It does not exhaust the quality of the bat that makes it different from a purely engineered object.
This article began as an inquiry into the subjective matter of form and how to treat aesthetics in design. It is apparent that at the core of the matter lies the subjective nature of design and that which makes design qualitatively different from other problem-solving activities such as planning and engineering. So, alluding to Nagel and his discussion of subjectivity, the relevant question here could be "What is it like to see a bat?" To see as a designer and to create as a designer is to do so in a distinct and unique way. Is design research over-looking this? In so doing, does design research extend the meaning of the term design too far? As Herbert Simon (I996, p.III) wrote "not only engineers design, all who devise courses of action aimed at changing existing situations into preferred ones..."

\section{THE EVOLUTION OF DESIGN RESEARCH}

The starting point for this section is the notion that design research has focused (not unreasonably) on I) method and 2) objectives. There has also been some attempt at dealing with aesthetic aspects from cognitive and user-judgement viewpoints. This section is divided into a short description of these approaches.

\section{Methods and objectives}

Frayling (1993, p. 98) makes the distinction between an expressive idiom and a cognitive one. Design straddles those two but the emphasis in research is usually on the cognitive. Two authors can be cited as inspiration for this second avenue of inquiry, namely the cognitive approach, though there are other candidates (e.g. Rittel and Webber I973; Krippendorff, 2006). Regarding methods, Jones (I97I) lays out the ground work for research by attempting to characterize the process of designing. The I97I book resulted from the initial debates of the design methods movement. This movement came in response to the perceived deficiency of natural science-inspired design (Glanville, 20I2) meaning hardsystems methods (Broadbent, 2003). Regarding objectives, Papanek (I972) 


\section{The research is dealing with what is perhaps necessary for a designed outcome but not sufficient."}

forcefully argued about what design was for, making that point that design had to address the needs of society and to take moral responsibility. Typically, texts such as Papanek's dealing with objectives make prescriptions about what design should achieve: less waste and less pollution and to address social ills such as poverty and inequality.

The design methods approach has branched into two strands. One is more managerial in outlook (e.g. Jones I97I), focusing on the structure of the process. That means it looks at the steps of the process and their interrelation and it is neutral on the stated goal. This has been termed the Science of Design (Gasparski and Strzalecki, I990) and an example of research in this vein would be Dorst (200I). The second sub-strand of the methods approach involves quantitative analysis of user's perception of design objects or of the performance of the objects, or both. An important point is that the second strand is morally neutral and deals with quantitative or measurable parameters. Its aim is to assist designers develop more acceptable consumer goods.

The design objectives approach has evolved with a focus on beneficial outcomes such as sustainability, design for disability and the extent of user involvement (e.g. co-design, participatory design). It has a strong moral tone, and is concerned with ethics. Some research of this type has technical content e.g. which materials to use for sustainability or how to conduct user-research with the elderly, marginalized or disabled (e.g. Clarkson et al. 2007). The second strand naturally requires a design methodology (e.g. Steinfeld and Maisel, 20I2). That said, it may be harnessed to any available design methodology if they it achieves the required ends. However, objectives- focused design research tends to draw on soft systems methods rather than hardsystems methods (see Broadbent, 2003) as does the design method outlined by the Cambridge Engineering Design Centre (EDC, 20I7).

These two strands, methods and objectives, can be also called respectively means focused and ends focused design. There are hybrids of the two where an attempt is made to both shape the design process and to suggest a values-determine outcome. Inclusive Design, for example, embodies both a methodology and a set of preferred design objectives (Clarkson et al. 2007).

Both means-focused and ends-focused design are entirely valid ways to consider design activities. However, they do not as a general rule, make any claims about the aesthetic nature of designed objects. One qualification is that both named approaches to design a) assume that the resultant objects are aesthetically satisfactory, or b) that acceptable forms are a natural success criteria or c) that aesthetic standards are insufficient to justify the outcome of the design process. Point (c) rests on the idea that even if an informal and unstructured "intuitive" design approach worked in one instance it is not reliable or repeatable for other instances. Any instances of failure will be unacceptable and Inclusive Design, for example, is conceived of as a means to avoid design failure. A second qualification is that Design for All (particularly Inclusive Design) addresses the psycho-social impact of aesthetics by its preference for forms that avoid stigmatization of the user (Langdon et al., 2012). However, the literature on Design for All does not delve deeper into what characterizes those forms apart from their ergonomic impact (e.g. large buttons, easy-to-read graphics and easy-grip forms) or whether the user deems them ugly or not.

The two-strand categorization presented here is not comprehensive or exclusive. Bruce Archer (I98I) was able to identify ten areas of design research (only two among them are relevant here so the other eight will not be listed for reasons of space). Corresponding to a means-focused approach is Archer's Category 4, design praxeology, which is "the study of the nature of design activity, its organisation and its apparatus". Aesthetics are mentioned is under Category Io, Design Axiolology which is "the study of worth in the design area with a special regard to the relationships between technical, economic, moral, social and aesthetic values”. Aesthetics, or the subjective aspect of design are, one could contend, important enough to justify a separate category.

\section{Design Research on Aesthetics}

There is research on the aesthetics of products which is primarily the analysis of consumer preferences regarding the appearance of designed objects (e.g. Hagtvedt and Patrick, 20I4). This research addresses what consumers prefer rather than the creation of the objects. The analysis may result in a recommendation concerning how future products should look or how to target specific users. This work can be characterized by its basis in hypothetico-inductive reasoning. A hypothesis is proposed and tested as to whether a particular formal characteristic is more or less attractive to customers using standard marketresearch and social science procedures. It is primarily quantitative in nature.

Even qualitative research tends towards a hypothetico-deductive model. The researcher tries to convert qualitative text data into something quantitative. Such work deals with what the consumer thinks or possibly with the analysis of the design process regarding the methodology.

Is that sufficient? Consider the hypothetical case of joints between parts in product design. David Pye (I964) noted that it is often the case that perceptions 
of quality reside in the craftsmanship of joints. Would typical design research as listed above be sufficient to address perceptions of quality and their meaning? A process-based inquiry centered on interviews with designers would not capture the character of the issue. Quantitative surveys of users would measure perceptions of the object, not the object itself (e.g. Hagtvedt and Patrick, 20I4; Hoegg et al 2010; Shih-Wen et al 2008; Sonderegger and Sauer, 2010; Tuch et al 20I2). A numerical study of joints (types and frequency of use) would not throw light on the aesthetics of the subject matter. There isn't a “theory” of joints and numerical data about their frequency of use would not address how they are perceived. A similar condition pertains for curvature, proportion, volume, colour and texture although all can be quantitatively described. So, leading from this it would appear that a significant element of design is beyond discussion if it does not fit into a natural science or social science box. The qualities of Grace's bats (Fig I) seem a long way from Frayling's design axiology.

Work also exists on a cognitive and psychological understanding of how objects are viewed e.g. Weber (I995), Norman (2005) and Desmet and Hekkert (2007). Weber considers the aesthetics of architecture with reference to Gestalt theory and spatial perception. As noted in Herriott (20I6) Weber does not pro- vide a means to address what Kant refers to as a pure aesthetic moment. Work on emotional design (Norman; Desmet and Hekkert) assumes that objects' aesthetic qualities matter alongside extrinsic aspects like product meaning.

Of these two last groups (qualitative research and cognitive), it is the cognitive approach that comes closest to the aesthetics of design but is also situated in a hypothetico inductive tradition. The work underlying this follows a natural science approach as to how design objects are perceived but could also be valid for explaining how any element of the environment may be understood. The cognitive approach doesn't deal with what might be called the depth of the design. For example, it might be correct that the elegant forms of Rams' work at Braun in the I96os and I970s are satisfying because of the strict ordering of the elements but it does not exhaust the description of the object or fully account for its effect.

Figure 2 is schematic representation of design research as outlined in this paper. For clarity the path from methodsand objectives-focused design research are shown leading to quantitative and qualitative research approaches as two duplicate pairs of boxes. Hybrids of these approaches exist. The aim of the diagram is to make clear that design research can be conducted without reference to aesthetics.

To summarise the foregoing: design

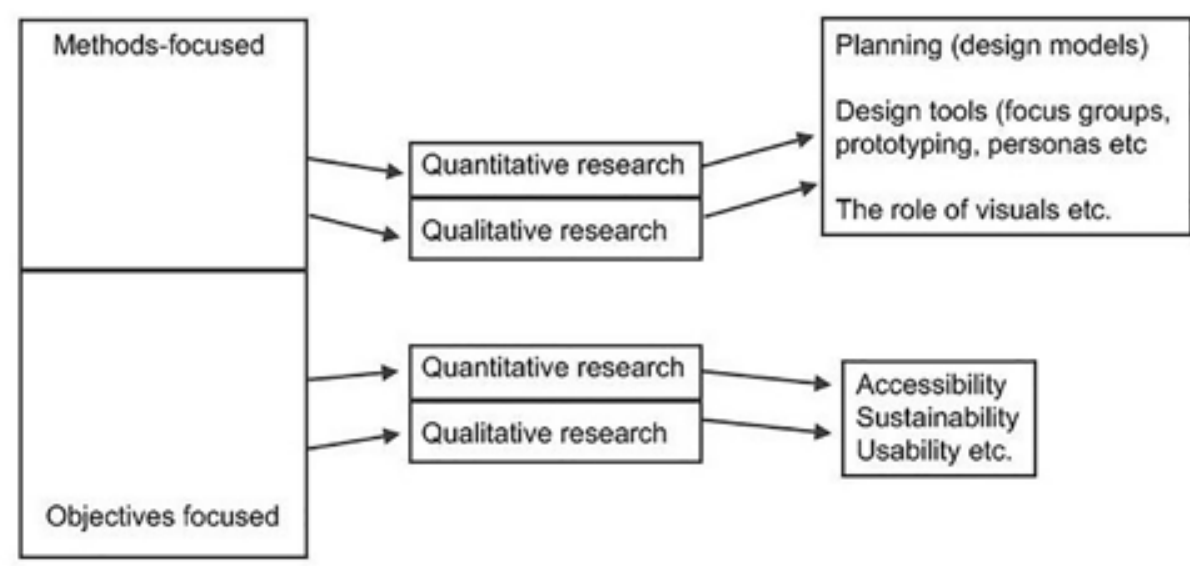

Figure 2. Design research relations. research has produced a body of work that does not fully address what distinguishes expressively design objects from what might be called design-neutral objects which are machine tools and intangibles (services and values-based outcomes e.g. accessibility or sustainability). The research is dealing with what is perhaps necessary for a designed outcome but not sufficient.

\section{THE CORE OF DESIGN}

So, where does this leave the core of design? And what is the core of design? The answer to the first is that design research might be ceding the essential aspect of design to management studies: a soft-systems design methodology that could be used quite as well to plan a new organizational structure or a new urban district as it might be used to design a visually-rich consumer product. Or it could be used by individuals who are not designers to deploy design process models to solve planning problems. An example of this is the widespread use of "design thinking", which might be summed up as the use of sticky notes, marker pens and knapkins (e.g. Roam, 2008).

The second question, about the core of design, is highly contentious. A full answer to this has not yet been developed. Kroes et al. (2009) offer the explanation that, in contrast to engineers, designers tend to interpret problems expansively and to employ qualitative data. Engineers are reductive and focused on the quantitative: "Designers tend to expand the scope of their problem to go beyond the everyday while engineers tend to reduce the scope of their design problems to the narrowest possible empirical criteria" (Kroes et al. 2009, p.5). The authors thus refer to design and engineering as having separate “epistemic communities" (Kroes et al. 2009, p.5).

Figure 3 shows a possible mapping of design in relation to its necessary elements: art, planning (which is a synonym of management activity), engineering (or the technical) and social 
science. The four terms have hybrids where the activities overlap. The diagram positions service design outside the field of engineering but within planning and social science. With engineering (which is synonymous with narrow functionality) and social science the hybrid of urban planning emerges. Design is where all four parameters overlap. It includes architecture which is merely building design.

An interesting possibility that allows for service design to be considered an aesthetically-orientated discipline is that the graphic representations of the abstract service might be judged on their aesthetic merits (clarity, simplicity, intuitive qualities) by the designers. From this point the aesthetic considerations might not be perceived by the end user but only by the designer. For this paper I wish to focus on tangible design outcomes.

For this article I propose that design is that which designers can uniquely do and which other problem-solving professionals do not. Design, by this pragmatic definition, is the use of visual representations to conceive of and produce objects which have an expressive aesthetic quality. It is the intersection of art sensibility and socio-technical requirements. What the designer can do that the mere user of "design thinking" cannot is to conceive of a not-yet-existing object, produce an accurate visual representation and then judge three dimensional instances (hereafter "instance") of it against the aesthetic ideal expressed in the images. There is a feedback between the drawing which will show an aesthetically correct form and the instance of it. If the instance has a feature which one would not draw in that way, the instance is amended to conform to the ideal. To put it very simply, the instance is judged against the question "would one draw it like that?" If the answer is no, the instance is corrected.

Figure 4 shows the four way relationship between the designer, the drawing, the idea and the instance. There are two start points for the idea of the new object $\mathrm{X}$ : I) a mental image or 2) the act of drawing. A third is a hybrid of the two in which abstract ideas constrain the range

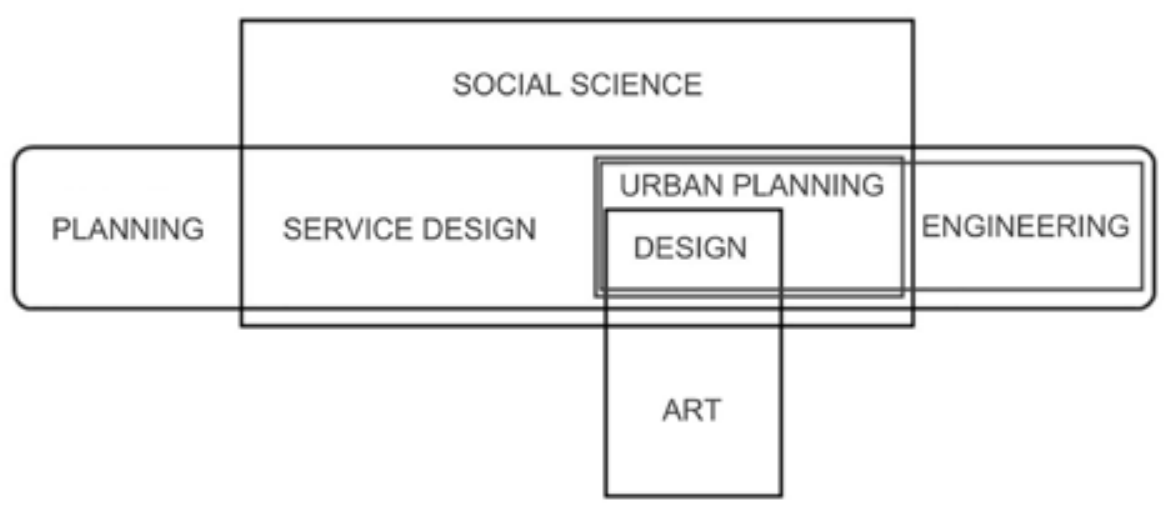

Figure 3. Art, planning, engineering and social science's relations to design.

of forms permissible for the image. I will deal with cases I and 2 .

In case I the designer has an idea with aesthetic content, the idea of the new object X. That idea is considered for its formal and conceptual content. Formal content would encompass the object's intended appearance. Conceptual content might involve values-based assessments such as I) if the object is feasible in principle (can it be made), 2) whether the object is morally acceptable at some level (should it be made) or 3) its fitness for purpose (will it work as intended). A robust wooden chair would pass the fitness test, for example, if one wanted to design furniture for an outdoor setting. A Louis XV-style chair might fulfil I and 2 but might not be conceptually correct for use in a large auditorium or a busy airport lounge.

When the idea passes the tests of formal and conceptual acceptability it can be drawn and re-drawn. The re-sketching process involves the drawing being assessed in itself (is it a good drawing) and in reference to the idea of object X. Producing a three dimensional representation of object $\mathrm{X}$ is needed to test the validity of the most acceptable drawing. That instance will be compared to the drawing and to the idea of object $\mathrm{X}$ on the basis of its formal and conceptual content.

In case 2 the designer, more or less constrained by verbal (a key word) or abstract notions (the feeling of the intended result e.g. a drawing that evokes the feeling of humour or Frenchness). She or he sketches freely and then assesses the ideas as they develop on the page. The idea is then considered in the light of formal and conceptual content as per case I. This process results in the idea of object X evolving in formal terms. The designer uses the two-dimensional drawing to first create a place-holder elements of which are added, deleted or amended. This part is partially intuitive and partially involves abstract reflection such as "what is causing that effect?" or "is that effect in line with the design's requirements".

From this one can understand that the creative, aesthetic aspect of design is occurring in the interaction between the idea of the object, its visual appearance on a two-dimensional page and in the mind of the designer. The designer both creates the shape unselfconsciously but also self-consciously reflects on that shape and alters it in a series of iterations.

When the object is realised as a threedimensional instance (such as a hard model or CAD model) the interaction becomes more complex. In satisfying some criteria inherent in the $2 \mathrm{D}$ drawing and the idea of object X, there usually emerges new, previously unconsidered elements that are in conflict with the ideal of an acceptable form, as shown on the drawings. One scenario might be when the needs to satisfy the appearance of the object from two views produce an appearance unacceptable in a third. A concrete example is known from automotive design when the front and side elevations can't be reconciled from the three quarter view or when the side elevation 


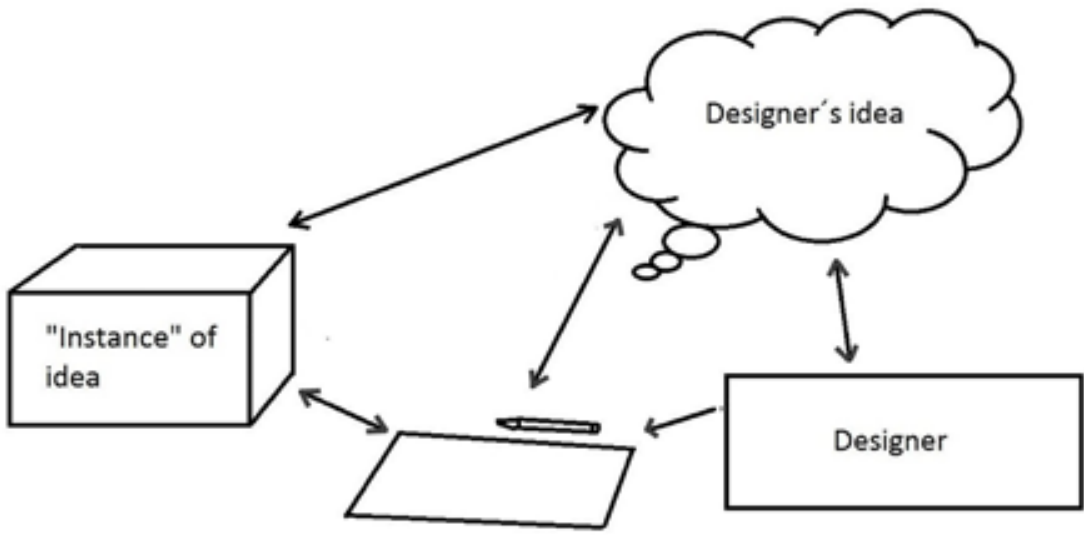

Figure 4. The relation of the design, idea, drawing and instance.

is not acceptable in three dimensions due to scale and optical effects. To adjust for perspective effects large objects such a motor cars are usually styled with more curvature than would be needed to produce an acceptable two-dimensional drawing. From this it is apparent that design activities focused on appearance are not purely conceptual or paper-based but rely also on aesthetic awareness in assessing three-dimensional instances. The assessment of three-dimensional forms overcomes the difficulty of representing complex objects seen from atypical angles. Drawings of objects from extreme angles are rare because they tend to produce shapes that are hard to assess. Drawing deals with the presentation of new forms in archetypal view. Three dimensional models test these by making visible all possible viewpoints, with each one satisfying the criteria of being acceptable if drawn from that view, were the designer able to visualise it.

The result of this process is a prototypical three-dimensional model which satisfies the aesthetic requirements from all viewpoints. If translated back a twodimensional drawing, the result is what one would draw if one had sufficient drafting skills.

In applied design, production requirements and other demands may force the object away from the drawn ideal. It is the task of the designer to ensure that the produced object is as close as possible to what one would draw, if entirely free. Design is thus always a compromise (see Pye, 1964) but one that aims to compromise in a certain direction. A designed object is thus one which has the potential to produce in the viewer what Kant calls a pure aesthetic moment (Kant, 2007; Allison, 200I; McConnell, 2008).

To link this back to the introduction, the design methods and design objectives strands of design are neutral on this process and the topic of the pure aesthetic experience. Design research in general is mute on the aesthetic aims of design other than, in some cases, to measure approval or to understand cognitive processes of visual assessment.

This section has described the relation of design to art, planning, social science and engineering. It has also described the role of the visual and the assessment of visual qualities during creative designing. The next question relates to addressing that aspect of the design process which is exclusive to the domain.

\section{INTUITION VERSUS PROCESS}

In this section I turn to Hillier (I998, p. 37) who asked how much design should be regarded as a legitimately intuitively process as opposed to one that:

"...is intuitive by default, and awaiting emancipation to a systematic procedure." The design methodology strand of design research is based on the assumption that design can be systematised. It can be but at the possible expense of treating that which makes design distinct from engineering or planning.

Hillier's question forces an analysis of what design is. It exposes a conflation of two related but different processes: the technical aspect of design and the creative aspect of design. The tendency to focus on that part of design focused on systematic procedure has produced a school of design not dissimilar to engineering. There was a point when it was a radically creative idea to eliminate decoration, as new products so designed could be seen in the context of the world of the old, decorative-arts approach to design (Loos, I9I3; Michl, I995). Today, many western people live in post WW2 constructions; minimalist, "engineered" designed objects are indistinguishable from engineered objects (See Fig 5. a Danish light switch). That is one consequence of a focus on the technical aspect of design. The technical approach may make it impossible to see the bat as a designer would.

We must look at the alternatives put forward by Hillier (1998). The question requires that one can define and recognize the legitimacy of intuition. There is a problem that intuition and legitimacy might not be compatible terms. To be legitimate means to conform to rules or to be defended with logic or justification. Taking the second meaning as more relevant, the intuition is justifiable if the results are satisfactory. So, the test of the design process is whether the results are satisfactory, that they meet the stated requirements. In plain terms this is to say the ends justified the means. An example: the wish to make a good-looking object. Is the object good-looking? If yes, then the process is justified. By that definition, the design methods approach loses its power, at least applied to industrial design. The recognition of the legitimacy of the design is a non-trivial problem. As shown above, to be legitimate means to be defensible by logic or justification. Since design is not philosophy, it is not enough for the formal logic to be correct. If, however, we allow that the defense is a logical argument then logical 
terms must correlate with aspects of reality rather than only internal logical consistency. For example, the form of the object must seem appropriate to its stated function (loosely defined). To test the legitimacy of the process one must have a record of the process. That is usually not the case. But assuming a documented design process, one could show evidence leading to the conclusion. Then it could be said to have been a legitimately intuitive design process. But the problem now is that an intuitive design process is usually obscure one: the designer may have simply chosen a reclining rectangular form as a basic theme without a priori reasoning. If the process was accurately and fully documented, the problem still remains that the success criteria ("is it a satisfactory design?") rely on essentially subjective estimations. On the other hand, the more an object and a process can be made to conform to objective criteria of fitness the less interesting the design object is and the less likely it would be recognized inter-subjectively as a piece of design (see Figure 5). It is easy to see if a light switch has met defined requirements but the object is not aesthetically rich. It is less easy to see if an armchair or motor car have met defined requirements and these are objects designed with typically sparse documentation and much reliance on intuition.

Few would call a light switch a "designed" object; it is more the result of engineering decisions. Aspects of the armchair or motor car are also engineering decisions but they are not the totality of the object. The question remains: is the shape of the striking car, attractive kettle, or "iconic" armchair legitimate or not? In essence, there are no objective rules-based ways to test the legitimacy of the design other than to ask if people like the results (appearance, functionality). If the answer is yes, the process is legitimate regardless of what it entailed.

This argument has shown that if design is legitimately intuitive, if the ends justify the means, then there appears to be little incentive in the development of procedures for its management.
Hillier's question also requires that we must disentangle the elements of "design" because depending on how it is defined (a perennial problem) not all of design is related to intuition, nonverbal processes or ends. One part is focused on quantitative factors and can be explicit and the other part is focused on the aesthetic which tends to be nondiscursive and intuitive, that is the part dealing with pure form. Essentially, there is a tension between the extent to which design can be made to conform to an objectively literal model and to possess the richness of designed objects that sets them apart from engineered objects.

\section{ADDRESSING FORM}

Hillier (I998) proposes the idea that in dealing with configuration (meaning form) designers are engaging in a non-discursive process. He writes that "we have no words and concepts that describe it at anything like the complexity at which we create it and experience it in the real world" (ibid: p.39). This is an elaborate way of saying one might need a thousand words to describe a picture and still not capture its character. More words yet are needed for the process of creation of the picture. In Nagel's terms, it is (I) hard to characterise what it is a designer experiences subjectively and it is (2) hard to characterise verbally what we perceive visually. Understanding design involves both (I) and (2). Fig 2. Demonstrates how this problem is bypassed in design research.

Design researchers might want to consider the study of the object from the standpoint of the designer's perception and the general perception of the user. If designers and design researchers can engage with objects rationally at that level then it could translate into a better four way process (See figure 2). This would be distinct from the "the Science of Design" which Cross (200I) describes as "the study of the principles, practices and procedures of design" inasmuch as this approach does not get close enough to the subjective, intuitive nature of design nor on how designed objects are perceived.

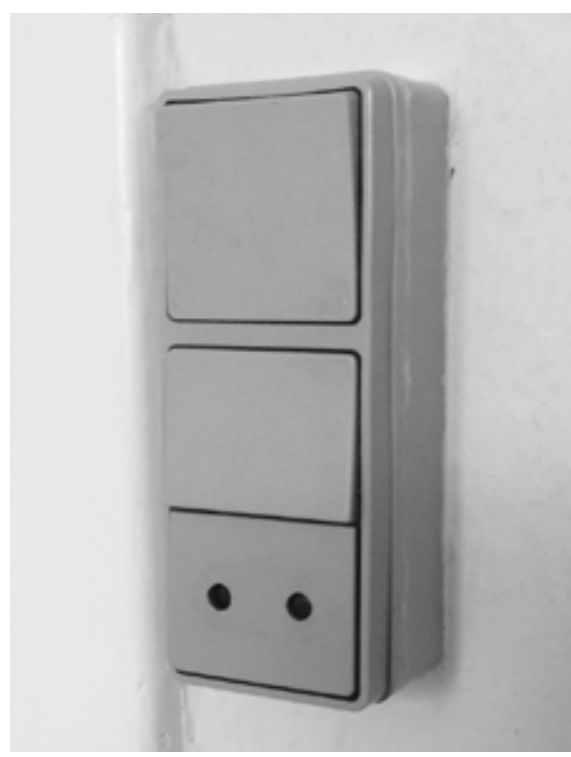

Figure 5. Danish light switch.

There is some value to considering the meaning of form in the way that one also considers the meaning of words, artworks and actions. This can be broken down into this (non-exhaustive list)

I) Functional meaning: the form is supporting the function or the form is in accord with the function. An example might be an item of medical technology with simple, geometrical shapes.

2) Kinetic meaning: Cheryl AknerKoler's (I995) concept of forces explains how the shape of objects is compared the known behavior of material. An example might be a curved surface that looks as if it has been subject to a force.

3) Analogical meaning: the object's resemblances in part or in whole. An example is the front end of a motor vehicle where the main elements seem to resemble a stylized human face.

4) Relational meaning: viewers can infer from an object how much effort was expended to make the object and how valuable the materials are. An example from product design is the effect of lead-in curvature on surface transitions which looks to be of higher quality than cruder curvature transitions (tangency and positional matching). 


\section{CONCLUSION}

The conclusion to be drawn from this is that design research must make more use of first-hand analysis of designed objects. This means offering a description of the object along with a reasoned analysis for that opinion. What is then possible is for the reader to judge the argument made against the object it relates to. One can agree or disagree. This mode of research is not intended to replace the other modes. It does however bring into design research a mode of discourse that addresses the intuitive and non-discursive aspects of design in a way analogous to architectural and film criticism. Of course, architecture and film are not identical to design. Important similarities are that they are complex and visual.

So long as design research attempts to deal with the objective aspects of design only it underplays the subjective, aesthetic phenomena that distinguish design from engineering and planning. If "old school" design paid insufficient attention to objective research, it does not follow that design research itself should disregard the subjective nature of a design and designing. To reformulate that, "old school" design often relied on the designer's intuition, tacit knowledge and personal preferences (see Polanyi, i966). The design process may have been unstructured and unplanned. The design methods movement articulated the hazards of this approach and attempted to formalise design in order to avoid negative outcomes such as a poor fit to users' needs and other problems.

The previous section should now be related back to Hillier (I998) who asked if design "...is intuitive by default, and awaiting emancipation to a systematic procedure." From the foregoing, the argument has been that the definition of a systematic procedure does not capture the intrinsic element of design, namely the subjective aspect. Parallel to that, design research (by which is meant here systematic research into design) has not dealt satisfactorily with that part of design and thus it tends not to address what it is in design objects that makes them distinct from engineering objects.
Design research should be able to address the aesthetic and subjective aspects of design objects since this is what makes them worthy of attention and that which puts them into a distinct class. Design is a discipline that encompasses methods that draw on natural science and social science approaches. However, there is an aspect of it which can be characterised as belonging firmly to the arts and requires informed and analytical but, ultimately, subjective approaches. A way to think about this is to draw on Bent Flyvbjerg's (2006) argument for case studies and consider the designed object and the researcher's view on it as a case. Turning to the other side of design, the creation of designed objects, both researchers and designers might usefully accept the value and also the limitations of attempting a fully systematic approach to design. It is a reasonable hypothesis that systematic design methods reduce the likelihood of design failure. There is also the risk that the scope of design is reduced to be as close to engineering design as to be indistinguishable. A case could be made that designers act as if their work is solely the result of systematic procedure when in all likelihood the forms are really the result of moments of intuition and inspiration set inside a systematic procedure ("caged intuition"). The consequence of this is that the designer dodges responsibility for the result by at least implying that it is the outcome of objective procedure. As Michl (I995) shows, the programme is selected by the designer and so is the procedure. No design is really the result of an objective process and nor is it true that when a designer sees a bat, they see only value-free geometry. Designers see bats and other things in a way informed by aesthetic understanding and they create things in the same way. Design research should address this in ways as diverse as the effects design objects have on the viewer.

\section{REFERENCES}

Akner-Koler, C. (I994) Three Dimensional Visual Analysis. Stockholm: University College of Arts, Crafts And Design.

Allison, H. E. (200I). Kant's theory of taste: a reading of the Critique of aesthetic judgment. Cambridge: Cambridge University Press.

Broadbent, J. (2003). Generations in design methodology. The design journal, 6(I), 2-I3.

Chalmers, D. J. (I996). The conscious mind: In search of a fundamental theory. Oxford: Oxford University Press.

Clarkson, J., Coleman, J., Hosking, I., (2007) The Inclusive Design Toolkit. Cambridge: Springer.

Cross, N. (200I). Designerly ways of knowing: Design discipline versus design science. Design issues, I7(3), 49-55.

Desmet, P., \& Hekkert, P. (2007). Framework of product experience. International journal of design, I(I).

Dorst, K., \& Cross, N. (200I). Creativity in the design process: co-evolution of problem-solution. Design studies, 22(5), 425-437.

Engineering Design Centre (20I7) inclusivedesigntoolkit.com (accessed March I5, 20I7)

Flyvbjerg, B. (2006). Five misunderstandings about case-study research. Qualitative inquiry, I2(2), 219-245.

Frayling, C. (I993). Research in art and design. In Grand, S. Jonas. W (eds.) Mapping Design Research. Basel: Birkhauser.

Gasparski, W., \& Strzalecki, A. (I990). Contributions to design science: Praxeological perspective. Design Methods and Theories, 24(2), 3. 
Glanville, R. (2OI2) Re-searching design and designing research. In Grand,

S. Jonas. W (eds.)

Mapping Design Research. Basel: Birkhauser,.

Grace, W. G. (I89I). Cricket.

JW Arrowsmith.

Grand, S., \& Jonas, W. (20I2). Mapping design research: positions and perspectives. Birkhäuser Verlag GmbH.

Hagtvedt, H., \& Patrick, V. M. (20I4). Consumer response to overstyling: Balancing aesthetics and functionality in product design. Psychology \& Marketing, 3I(7), 5I8-525.

Herriott, R. (20I6). On Ugliness and the Automotive. Proceedings of the 7 th Ascea Conference on Aesthetics.

Hillier, B. (I998). A note on the intuiting of form: three issues in the theory of design. Environment and Planning B: Planning and Design anniversary issue, 37-40.

Hoegg, J., Alba, J. W., \& Dahl, D. W. (20I0). The good, the bad, and the ugly: Influence of aesthetics on product feature judgments. Journal of Consumer Psychology, 20(4), 4I9-430.

Jones, J.C. (I970) Design Methods: the seeds of human futures. London: John Wiley \& Sons.

Krippendorff, K. (2005). The semantic turn: A new foundation for design. London: Taylor \& Francis CRC.

Nagel, T. (I974). What is it like to be a bat?. The philosophical review, 83(4), 435-450.

Kant, E (2007). Critique of Judgement. (Trans.) J.C. Meredith. Oxford: Oxford University Press.
Kroes, P., Light, A., Moore, S., Vermaas, P. (2009) Design in Engineering and Architecture; towards an Integrated Philosophical Understanding. In Vermaas, P.E., Kroes, P., Light, A., Moore, S. (eds.) Philosophy and Design: from engineering to architecture. London: Springer

Langdon, P., Clarkson J., Robinson, P., Lazar., Heylighen, A (eds) (20I2). Designing inclusive systems. London: Springer: London.

Loos, A (I9I3) "Ornament und verbrechen”. Cahiers d'aujourd'hui. Issue 5.

Love, T. (2000). Philosophy of design: a meta-theoretical structure for design theory. Design studies, 2I(3), 293-3I3.

McConnell, S. (2008). How Kant might explain ugliness. The British Journal of Aesthetics, 48(2), 205-228.

Michl, J. (I995). Form follows

WHAT. The modernist notion of function as a carte blanche, I, 20-3I.

Norman, D.A, (2004) Emotional Design: Why we love or hate everyday things. New York, NY: Basic Books.

Papanek, G. (I972). Design for the real world. New York, NY: Pantheon

Polanyi, M (I966). The tacit dimension. Chicago: University of Chicago Press

Pye, D. (I964) “The nature and aesthetics of design". London: Herbert Press

Rittel, H. W., \& Webber, M. M. (I973).

Dilemmas in a general theory of planning. Policy sciences, 4(2), I55-169.

Roam, D (2008). On the back of a knapkin. Penguin: London.

Simon, H. (1996). The Sciences of the artificial. MIT Press, Cambridge, MA
Shih-Wen, H., Fu-Yuan, C., Chong, S.C. (2008) Applying aesthetic measurement to product design. International Journal of Industrial Ergonomics 38, 910-920.

Sonderegger, A., \& Sauer, J. (20I0). The influence of design aesthetics in usability testing: Effects on user performance and perceived usability. Applied ergonomics, 4I(3), 403-4IO.

Steinfeld, E., \& Maisel, J. (20I2). Universal design: Creating inclusive environments. John Wiley \& Sons.

Tuch, A., Roth, S., Hornbæk, K., Opwis, K., Bargas-Avila, J.A (20I2). Is beautiful really usable? Toward understanding the relation between usability, aesthetics and effect in HCI. Computers in Human Behavior 28, I596-I607.

Weber, R (I995) On the aesthetics of architecture: a psychological approach to the structure and order of perceived architectural space. Avebury: Aldershot. 